\title{
Mitteleuropa in den politischen Vorstellungen der böhmischen Aristokratie in der frühen Neuzeit: Von der anti-osmanischen Allianz zur evangelischen Konföderation ${ }^{1}$
}

\section{EINLEitunG}

Mitteleuropa ist im tschechischen politischen Denken und insbesondere in der politischen Praxis des böhmischen oder tschechischen Staates als Problem der Koexistenz und staatsübergreifenden Integration seit dem Hochmittelalter präsent - eine Präsenz, die bis in die Gegenwart fortdauert. Dies bedeutet nicht, daß eine lange Reihe in sich geschlossener theoretischer Konzeptionen bzw. politischer Visionen für eine künftige Ordnung des mitteleuropäischen Raumes das Licht der Welt erblickt hätte, wenngleich auch derartige $\mathrm{Zu}$ kunftsvisionen - insbesondere im 19. und 20. Jahrhundert - entstanden ${ }^{2}$. Die geopolitische Stellung eines relativ kleinen Landes und eines zahlenmäßig kleinen Volkes mitten in Europa weckte eher das Bedürfnis nach pragmatischen Lösungen, die der machtpolitischen Konstellation Mitteleuropas und dem Bemühen entsprachen, die aktive Rolle des böhmischen/tschechischen Staates im Verhältnis zu seinen unmittelbaren Nachbarn aufrechtzuerhalten. Aber auch hier entstanden - insbesondere im aristokratischen Milieu der beginnenden Neuzeit - Visonen von Mitteleuropa, die bislang noch immer einer gebührenden Bewertung harren. Ziel dieses Beitrags ist es, gerade auf zwei in Vergessenheit geratene und in ihrer Ausrichtung gegensätzliche Konzeptionen aufmerksam zu machen, welche in Böhmen zu Beginn der Neuzeit entstanden und beide die machtpolitischen und konfessionellen Verhältnisse dieses Raumes widerspiegeln, zugleich aber den Versuch unternahmen, den Anteil des böhmischen Staates am europäischen Geschehen zu bewahren.

\section{Ausgangspunkte}

Die politischen Vorstellungen im frühneuzeitlichen Böhmen gingen vom Bewußtsein einer spezifisch komplizierten Realität aus, und zwar unter innen-

1 Text eines am 11. Dezember 2001 auf Einladung der Historischen Kommission der ÖAW im Rahmen des Arbeitskreises „Höfe des Hauses Österreich“ gehaltenen und mit den bibliographischen Anmerkungen versehenen Vortrags.

2 Ich denke hier insbesondere an die Vorstellungen der beiden bedeutendsten politischen Denker des 19. und 20. Jahrhunderts, den Austroslavismus František Palackýs und das moderne Europäertum Tomáš Garrigue Masaryks; aus der neuesten Literatur vgl. zumindest Miloš Havelka (Hg.), Spor o smysl českých dějin 1895-1938, Praha 1998; Jiří KoŘAlKa, František Palacký (1798-1876). Životopis, Praha 1998; František Šmahel (Hg.), František Palacký. Dějiny a dnešek, Praha 1999; T. G. Masaryk, Spisy TGM - Band 6 (Česká otázka. Naše nynější krize. Jan Hus), Praha 2000 (kritische Ausgabe mit ausführlichem Kommentar); Stanislav PoLák, T. G. Masaryk. Za ideálem a pravdou I-II, Praha 2000-2001 (die beiden ersten Bände der bislang umfangreichsten Biographie und Werkanalyse T. G. Masaryks). 
wie außenpolitischen Gesichtspunkten. Im internationalen Sinne gab es bereits im Mittelalter als Konstante der europäischen Politik die ständige Rivalität von vier mitteleuropäischen Staaten - Böhmens (seit dem Spätmittelalter der Böhmischen Krone), Polens, Ungarns und Österreichs -, in geringerem Ausmaß sodann zwischen den deutschen Territorialstaaten, ein Ringen, das in gewissem Umfang auch durch die universalen Ansprüche der römischdeutschen Kaiser beeinflußt wurde. Der schrittweise Untergang bzw. die Schwächung der sogenannten „nationalen“ Gründerdynastien (Babenberger, Arpaden, Přemysliden und Piasten) nach der Mitte des 13. Jahrhunderts rief wiederholt einen Zustand der Labilität hervor, in dem die Staaten und stärkeren Dynastien versuchten, ihre Macht auf das Territorium der zeitweise schwächeren Gegner auszudehnen. Die letzten Přemysliden und die ersten Habsburger an der Wende vom 13. zum 14. Jahrhundert, die Luxemburger und Anjou im 14. Jahrhundert, die Habsburger, Hunyadi und Jagiellonen im 15. Jahrhundert avancierten zu Repräsentanten sich ständig wiederholender Versuche, zumindest einige mitteleuropäische Staaten unter einem einzigen Zepter zu vereinen. Diese Versuche zielten stets auf ein annäherndes Gleichgewicht der vier Partner, scheiterten jedoch nach einigen Jahren bzw. Jahrzehnten. Eine wirkliche Wende bewirkte erst der äußere Druck, dessen Nutznießer in den zwanziger Jahren des 16. Jahrhunderts die Habsburger wurden, eine mit einem enormen politischen und militärischen Potential ausgestattete und von ihren westeuropäischen Besitzungen sich stetig ausdehnende Dynastie wurden. Die Vereinigung der böhmischen, österreichischen und ungarischen Länder unter der Herrschaft einer Dynastie gab diesem Raum eine neue Dynamik und leitete die divergierende Entwicklung der Länder der Habsburgermonarchie auf der einen und Polens bzw. des Königreichs Polen und des Großfürstentums Litauen auf der anderen Seite ein ${ }^{3}$.

Neben diesen äußeren Determinanten wirkten auf die Entwicklung des politischen Denkens in Böhmen auch innere Konflikte, die sich im Spätmittelalter auf das Problem religiöser Pluralität und die Konfessionalisierung des öffentlichen Lebens konzentrierten. Seit den zwanziger Jahren des 15. Jahrhunderts war die Bevölkerung des böhmischen Staates in zwei Lager geteilt, von denen eines die hussitische Vorstellung hinsichtlich einer Reform der Kirche und Gesellschaft unterstützte, während das andere eine solche ablehnte. Darüber hinaus spalteten sich die Anhänger der ersten (tschechischen) Reformation im Verlaufe der Zeit in weitere - miteinander konkurrierende - Bewegungen. Die Umgruppierung der politischen Eliten und ihres sozialen Hinterlandes wurden im 15. und 16. Jahrhundert ebenso wie die ideologische Abgrenzung der innerlich differenzierten Eliten im gleichen Zeit-

3 Die Literatur zu den Wandlungen Mitteleuropas an der Wende vom Spätmittelalter zur frühen Neuzeit nimmt heute quantitativ einen breiten Raum ein. Ich verweise daher an dieser Stelle lediglich auf einige grundlegende Arbeiten, die die Umformung dieses Raumes im Prozeß der Entstehung der Habsburgermonarchie beschreiben: Gerhard RITTER, Die Neugestaltung Europas im 16. Jahrhundert, Berlin 1950; Josef JANÁČEK, České dějiny. Doba předbělohorská 1526-1547, I/1-2, Praha 1968-1984; Hajo HolboRn, Deutsche Geschichte in der Neuzeit, I, München-Wien 1970; Kenneth J. Dillon, King and Estates in the Bohemian Lands 1526-1564, Bruxelles 1976; Robert J. W. Evans, The Making of the Habsburg Monarchy, 1550-1700. An Interpretation, Oxford 1979; Winfried EBERHARD, Monarchie und Widerstand. Zur ständischen Oppositionsbildung im Herrschaftssystem Ferdinands I. in Böhmen, München 1985; G. R. Elton (Ed.): The New Cambridge Modern History, II (second edition): The Reformation 1520-1559, Cambridge 1990; Alfred KoHLER, Karl V. 1500-1558. Eine Biographie, München 1999. 
raum zum entscheidenden Motiv im öffentlichen Leben und im politischen Denken in den böhmischen Ländern ${ }^{4}$.

Die Konflikte spielten sich jedoch nicht allein auf politischer, sozialer und konfessioneller Ebene ab, sondern zugleich auch im ethnisch-nationalen Bereich. Seit dem Hochmittelalter gab es einen latenten Konflikt zwischen dem Adel, der ebenso wie die übergroße Mehrzahl der Bevölkerung tschechischsprachig war, und dem Stadtpatriziat, das in Folge der äußeren Kolonisierung der böhmischen Länder mehrheitlich einen deutschsprachigen Charakter aufwies. In der Hussitenzeit erreichte dieser Konflikt zwischen dem tschechischen Hussitismus und dem universalen Katholizismus, der wiederum vornehmlich mit der deutschen Ethnie identisch war, seinen Höhepunkt. Das Luthertum im 16. Jahrhundert entschärfte zwar diesen Antagonismus, doch der neuerlich wachsende deutsche Einfluß in Böhmen und Mähren begünstigte wiederum die Ausbildung des Abwehrcharakters des tschechischen Nationalismus 5 .

An der Schwelle zur Neuzeit sah sich nämlich das politische Denken in Böhmen, insbesondere im Hinblick auf die zukünftigen Entwicklungsmöglichkeiten, gleichzeitig mit mehreren Schlüsselfragen konfrontiert. Dabei handelte es sich: Erstens um die dualistische Teilung der Macht zwischen Ständen und Herrscher; zweitens um das Verhältnis der Katholiken, hinter denen der Monarch sowie ein kleinerer Teil der Ständegemeinde stand, und den Protestanten, die im Adel und im Bürgertum in Böhmen und Mähren und nach der Durchsetzung des Luthertums auch in Schlesien sowie in der Oberund Niederlausitz ein deutliches Übergewicht besaßen; drittens um das Zusammenleben zwischen Tschechen und Deutschen innerhalb der Länder der Böhmischen Krone und um ihr Verhältnis zu den Landfremden; viertens um das Verhältnis zwischen den fünf Ländern der Böhmischen Krone zueinander sowie deren gemeinsame Beziehung zu den christlichen Nachbarländern; fünftens um die Haltung der Einwohner des böhmischen Staates als Teil der Christenheit gegenüber der wachsenden osmanischen Bedrohung ${ }^{6}$.

\section{Die antitürkische Allianz DeR Katholischen Christen}

Um die Mitte des 16. Jahrhunderts fand die Zukunftsvision, deren Schöpfer der böhmische Aristokrat Johann Zajíc von Hasenburg (geboren um 1492, ge-

${ }^{4}$ Grundlegend für die konfessionelle Entwicklung der böhmischen Länder vom 15. bis zum beginnenden 17. Jahrhundert sind: Ferdinand HREJSA, Česká konfesse, její vznik, podstata a dějiny, Praha 1912; ders., Dějiny křest’anství v Československu, II-VI, Praha 1947-1950; Rudolf Říčan, Dějiny Jednoty bratrské, Praha 1957; Winfried EBERHARD, Konfessionsbildung und Stände in Böhmen 1478-1530, München-Wien 1981; ders., Monarchie und Widerstand. Zur ständischen Oppositionsbildung im Herrschaftssystem Ferdinands I. in Böhmen, München 1985, František ŠMAHEL, Husitská revoluce, I-IV, Praha 1993 (2. Auflage, Praha 1995-1996).

5 Zur Entwicklung zwischenethnischer Beziehungen in den böhmischen Ländern vgl. Josef KuIK, Národnostní poměry v Čechách od válek husitských do bitvy bělohorské, Praha 1922; Alois MíkA, Národnostní poměry v českých zemích před třicetiletou válkou, Československý časopis historický 20, 1972, S. 207-233; František ŠMAHEL, Idea národa v husitských Čechách (2., ergänzte Auflage), Praha 2000; Jaroslav PáNEK, Italové, Nizozemci a Němci v rudolfinské Praze - některé formy a problémy soužití, Documenta Pragensia 19, 2001, S. 67-74, 362-364.

${ }_{6}$ Ein kurzer Abriß der Entwicklung des politischen Denkens sowie eine Charakteristik seiner Hauptvertreter bei: Jaroslav PÁNEK, The Political Thought in Bohemia and Moravia in the $16^{\text {th }}$ and $17^{\text {th }}$ Centuries, Odrozenie u Reformacja w Polsce 39, 1995, S. 133-139. 
storben 1553) wurde, ihre endgültige Ausformung7. Er war ein Vertreter eines alteingesessenen Herrengeschlechts, das von seinem Prestige her in der Stufenleiter des böhmischen Adels den elften Platz einnahm ${ }^{8}$; zugleich gehörte Johann Zajíc von Hasenburg umfangreicher Grundbesitz in Nordböhmen. In seiner Jugend hatte er eine allseitige sprachliche, literarische, historische, musikalische und naturwissenschaftliche Bildung erhalten. Darüber hinaus verfügte er über ein überdurchschnittliches literarisches Talent, auf das wir in diesem Umfang bei anderen böhmischen Aristokraten nur sehr vereinzelt stoßen. Johann Zajíc bereiste die Länder Mitteleuropas und besuchte auch Palästina, so daß er unter diesem Aspekt - noch vor dem wachsenden Interesse an Reisen in der Zeit der Renaissance ${ }^{9}$ - zu denjenigen adeligen Persönlichkeiten mit dem größten Weitblick gehörte. Der Schwerpunkt seines Interesses lag nicht in der aktiven Politik, da er hier keine solche Bedeutung erlangte wie einige seiner Vorfahren, vielmehr profilierte er sich als kulturschöpferische Persönlichkeit sowie als Organisator einzigartiger Theateraufführungen unter freiem Himmel. Gerade in seinen unter der Bezeichnung ,Sarmacia“10 überlieferten Memoiren propagierte er - ebenso wie in zwei theatralischen Schauturnieren - seine Vorstellungen hinsichtlich der Umwandlung des gesellschaftlichen und politischen Lebens in Böhmen, der Verbesserung der Beziehungen zwischen Tschechen und Deutschen sowie ihres gemeinsamen Kampfes gegen die Türken. Als Ergebnis dieser Überlegungen formte sich die Vorstellung von Mitteleuropa als einer christlichen, anti-osmanischen Gemeinschaft heraus.

Den Ausgangspunkt von Zajíc' Konzeption bildeten seine Erfahrungen beim Dienst am Königshof und bei Reisen ins Ausland. Als Inhaber des erblichen Hofamtes des obersten Truchseß (Tafelmeisters) des Königreichs Böhmen gehörte Johann Zajíc zu Beginn des 16. Jahrhunderts zu den führenden jagiellonischen Höflingen, und dementsprechend wurde er auch vom böhmischen und ungarischen König Wladislaw II. eingestuft. An der Schwelle zum Erwachsensein, im Jahre 1509, wurde er im Rahmen der Krönungsfeierlichkeiten auf der Prager Burg erstmals zum Ritter geschlagen. Diese Ehre widerfuhr ihm auch aus den Händen Kaiser Maximilians I. beim Treffen der Jagiellonen und Habsburger in Wien im Jahre 1515, als Johann Zajíc Zeuge der für die weitere Entwicklung Europas richtungweisenden dynastischen Allianz wurde. Die Erziehung im Geiste des mittelalterlichen Ritterkodex fand auch in den folgenden Jahren ihre Fortsetzung, wobei der dritte Ritterschlag im Jahre 1522 - im Zusammenhang mit der Aufnahme unter die Verteidiger des Heiligen Grabes in Jerusalem - ihren krönenden Abschluß bildete ${ }^{11}$.

Das ritterliche Ideal des Mittelalters spiegelte Johann Zajíc' persönliche Überzeugung wider, die er innerhalb der böhmischen Adelsgesellschaft zu

7 Ein Abriß seines Lebens vgl. bei Jaroslav PÁnEK, Paměti českého šlechtice z poloviny 16. století („Sarmacia“ Jana Zajíce z Házmburka), Folia Historica Bohemica 14, 1990, S. 17-36; hier auch Verweise auf die enstprechenden Quellen.

8 František Palacký, Popis staropanských rodů v Čechách r. 1500, Časopis Českého musea 5, 1831, S. 172.

9 Eingehender hierzu Jaroslav PÁNEK, Reisende aus Böhmen im Europa der Renaissance (Reisen als kultureller Faktor und als Katalysator der politischen Integration), Bohemia (Zeitschrift des Collegium Carolinum, München) 32, 1991, S. 338-367.

10 Österreichische Nationalbibliothek Wien, Cod. 8091; Jaroslav PÁnex (Ed.), Edice pamětí Jana Zajíce z Házmburka z roku 1553 (na základě rukopisu Rakouské národní knihovny ve Vídni, sign. Cod. Vindob. 8091), Folia Historica Bohemica 14, 1990, S. 37-98 (künftig zitiert als: J. Zajíc, Paměti).

11 J. Zajíc, Paměti, S. 74. 
verbreiten versuchte. Letztere verfolgte zwar mehrheitlich andere Interessen, doch sah sie sich gezwungen, Johann Zajíc schon allein wegen seines prunkvollen öffentlichen Auftretens zur Kenntnis zu nehmen. Diese Zurschaustellung zeigte sich unter anderem bei der Hochzeit mit der schlesischen Herzogin Margarete von Münsterberg, der Urenkelin König Georgs von Podiebrad, bei der Errichtung der prachtvollen Residenz auf Schloß Budin an der Eger und insbesondere bei der Veranstaltung adeliger Feste, auf denen in den Jahren 1544 und 1552 Zajíc' Visionen für eine bessere Zukunft szenisch zur Aufführung gelangten ${ }^{12}$.

In der szenischen Aufführung ging es um ein verhältnismäßig einfaches Geschehen und um eine allgemein verständliche Symbolik. Unweit des Budiner Schlosses spielte sich folgende Handlung ab: Inmitten der Kirchweihfeiern mischten sich unter die friedliebenden Christen türkische Spione. Nachdem sie sich davon überzeugt hatten, daß die einheimische Bevölkerung nicht auf eine Verteidigung vorbereitet war, gingen die Soldaten des Sultans zum Angriff über, säbelten ihre Opfer erbarmungslos nieder oder verschleppten sie in die Sklaverei. Unter den Angegriffenen fand sich jedoch eine Handvoll aufrechter Männer, die erbittert Widerstand leisteten. In den in Turnierform ausgetragenen Kämpfen mit den Türken demonstrierten die tapferen Christen diesen ihre wahre Stärke und retteten sich und ihren Angehörigen Leben, Freiheit und Ehre. Die Wiederbelebung des Ritterideals vermochte die äußerste Gefahr abzuwenden und bewahrte nicht allein die Würde des Adels, sondern rettete symbolisch auch die Zukunft des tschechischen Volkes sowie der bedrohten Christenheit ${ }^{13}$.

Johann Zajíc wußte nur zu gut, daß die anschauliche Theateraufführung leider allzu schnell in Vergessenheit geraten würde; daher bereitete er seine Vorstellung in überarbeiteter literarischer Form für eine Veröffentlichung vor. "Meine Ansicht vertraue ich meinem Volk an und gebe ihm meinen Rat", schrieb er programmatisch in seinen Erinnerungen, die er kurz vor seinem Tode fertigstellte ${ }^{14}$. Er tat dies in Briefform, die den böhmischen Humanisten des 16. Jahrhunderts nahestand, und widmete sein Werk Erzherzog Ferdinand II. von Tirol, dem Sohn des regierenden Königs Ferdinand I. von Habsburg und zugleich Statthalter des Königreichs Böhmen. Es handelte sich nicht allein um eine äußere Bekundung der Loyalität zu einem Mitglied der Habsburgerdynastie, sondern die Schrift verfolgte auch den Zweck, daß Erzherzog Ferdinand half, diese unter der aristokratischen Öffentlichkeit zu verbreiten. Darüber hinaus verband Johann Zajíc mit dem Statthalter das katholische Bekenntnis sowie das Verständnis für die Verhältnisse in Böhmen, durch welches sich dieser Habsburger in hohem Maße auszeichnete.

Die Schrift „Sarmacia“ von Anfang 1553 suchte einen Ausweg aus der beklemmenden Atmosphäre der ersten Jahre nach der Niederlage des ersten antihabsburgischen Aufstandes der böhmischen Stände (1547). Die Spannungen zwischen Herrscher und adeliger Opposition sowie zwischen Katholiken und Protestanten zeigten sich in einer Zeit, als sich westlich der böhmischen Grenzen eine protestantische „Fürstenrebellion“ abspielte und im Osten ein neuer Konflikt zwischen den Habsburgern und dem Osmanischen Reich drohte. Im übrigen näherten sich bereits mit der Errichtung des Paschaliks Buda (1541) die Grenzen des Osmanischen Reiches den Ländern der Böhmi-

12 Eingehender hierzu Jaroslav PÁNEK, Paměti českého šlechtice, S. 20 f. und 28 f.

13 J. Zajíc, Paměti, S. 77-82.

14 Ebd. S. 77 
schen Krone derart gefährlich, daß ein aufmerksamer Zeitgenosse die reale Gefahr nicht mehr leugnen konnte ${ }^{15}$.

Johann Zajíc, der bei jeder Gelegenheit seinen inbrünstigen Patriotismus bekundete, bewertete die Zuspitzung der Konflikte in beiden Lagern Mitteleuropas aus böhmischer Sicht. Er war sich dabei dessen bewußt, daß die auf deutschem Gebiet ausgetragenen Kämpfe keine unmittelbare Gefahr für Böhmen heraufbeschworen, auch wenn der Böhmenkönig darin involviert war. Demgegenüber begriff Zajíc die osmanische Expansion als die für seine Heimat größte Gefahr, die „zum Fall und - wie am Faden hängend - zum Ruin und zum Untergang hätte führen müssen "16, wenn die mitteleuropäischen Habsburger den Türken nicht permanent die Stirn geboten hätten ${ }^{17}$. Die apokalyptische Gefahr eines türkischen Einfalls verband sich in Zajíc ' Vorstellungen mit weiteren Katastrophen, die er mit eigenen Augen gesehen oder von denen er durch Augenzeugen bzw. zumindest durch Astrologen Kenntnis erhalten hatte, deren Prophezeiungen er nicht auf die leichte Schulter nahm. Erdbeben, Überschwemmungen, Mißernten, Pestausbrüche sowie weitere Epidemien verbanden sich mit Angst einflößenden Konstellationen der Sterne und belegten, daß das Gleichgewicht der irdischen Dinge weitreichend aus den Fugen geraten war. Sämtliche Erscheinungen in Natur und Gesellschaft signalisierten den Zorn Gottes über die verderbte Christenheit, ähnlich wie „die türkische Geißel, die, vom lieben Gott dem Herrn gesandt, auf uns gekommen ist"18.

Die kontrastreiche Zuspitzung des zeitgenössischen Zustands der Dinge und Vorstellungen hinsichtlich einer erforderlichen Ordnung Mitteleuropas besaßen im Falle von Zajíc eine starke persönliche Basis. Er selbst machte sich mit der türkischen Bedrohung auf seiner Reise ins Heilige Land vertraut, die er unmittelbar nach dem Fall Belgrads unternahm, zu einer Zeit, als Europa durch die Tatsache in Angst und Schrecken versetzt wurde, daß den Türken die weite ungarische Tiefebene offenstand und sie damit sozusagen freien Durchgang zum Herz des Kontinents besaßen ${ }^{19}$. Es handelte sich dabei nicht um ein augenblickliches Entsetzen, sondern um eine grundlegende Erschütterung der existentiellen Sicherheit, die zwar nicht alle böhmischen Adeligen in gleichem Ausmaß fühlten, doch für einen so scharfblickenden Intellektuellen und einen Menschen wie Johann Zajíc, der nicht allein für sich selbst Verantwortung sah, bedeutete eine solche Erfahrung offenkundig einen grundlegenden Lebenseinschnitt. In dieser Situation war es verständlich, daß er sich die

$15 \mathrm{Zu}$ den politischen und gesellschaftlichen Umständen von Zajíc‘ letztem Lebensabschnitt vgl. Josef JANÁČEK, České dějiny. Doba předbělohorská (1526-1547), I/2, Praha 1984, S. 299-332; Jaroslav PÁNEK, Stavovská opozice a její zápas s Habsburky 1547-1575, Praha 1982, S. 18-53.

16 J. Zajíc, Paměti, S. 40.

17 Zum breiteren Kontext dieser Vorstellungen vgl. Jaroslav PáNEK, Turecké nebezpečí a předbělohorská česká společnost, Studia Comeniana et historica XI/23, 1981, S. 53-72; eine wichtige Monographie zum frühneuzeitlichen Türkenbild in den böhmischen Ländern hat der junge Historiker Tomáš Rataj bearbeitet: Tomáš RATAJ, České země ve stínu půlměsíce. Obraz Turka v raně novověké literatuře z českých zemí, Praha 2002.

18 J. Zajíc, Paměti, S. 47.

19 Zur Eroberung von Belgrad und der daraus erwachsenen politischen Lage in Europa vgl. Carl Göllner, Turcica. III. Band: Die Türkenfrage in der öffentlichen Meinung Europas im 16. Jahrhundert, Bucureşti - Baden-Baden 1978, S. 80 f.; zum publizistischen Echo ders., Turcica. I. Band: Die europäischen Türkendrucke des XVI. Jahrhunderts I, Bucureşti - Berlin 1961, S. $88 \mathrm{ff}$. 
Vorstellung von einer möglichen Vernichtung der großen christlichen Reiche zu eigen machte, und zwar anhand des Byzantinischen Reiches. Einen anschaulichen Beleg hinsichtlich der erwarteten Katastrophen und Greueltaten, die von seiten der „unflätigen Heiden“ drohten und die das „allermächtigste griechische Kaisertum und viele andere christliche Länder“ heimsuchten $^{20}$, fand er in einem Schreiben des byzantinischen Kaisers Alexios I. Komnenos an den Grafen Robert I. von Flandern, dessen wortgetreue Übertragung ins Tschechische er in seinen Erinnerungen einfügte. Zajíc hatte offensichtlich keine Kenntnis davon, daß das vermeintliche Schreiben aus dem Jahre 1102 eine bloße Fälschung war, die den Kreuzzug nach Palästina rechtfertigen sollte; als wesentlich erwies sich für ihn, daß dieses Schriftstück zwischen dem 13. und 16. Jahrhundert ein Eigenleben entfaltet hatte und sich medial hervorragend als „Zeugnis“ für die Grausamkeiten eignete, die nach einem türkischen Einfall auch die mitteleuropäischen Staaten erwarten müß$\operatorname{ten}^{21}$.

Im Geiste eines providentiellen Denkens zeigten sich die grausamen Geschehnisse der Zeit, in der Zajíc lebte, als Ergebnis der Eingriffe einer erzürnten Vorsehung in die Beziehungen zwischen den Menschen und Völkern. Daher waren die zeitgenössischen Verwerfungen in den zwischenmenschlichen Beziehungen nach Zajíc' Meinung schlimmer als in den Zeiten alttestamentlicher Katastrophen, ein Umstand, dem auch die Frequenz und die Schwere der Strafen entsprach. Und die härteste Strafe - der rasch herannahende türkische Einfall - sollte erst noch folgen. Bislang hatten die strafende Vorsehung von einer endgültigen Abrechnung allein Christi Fürsprachen sowie der beharrliche Abwehrkampf der Habsburger abzuwenden vermocht. Doch war nun die höchste Zeit angebrochen, daß sich auch die Angehörigen des tschechischen Volkes selbst um die eigene Verteidigung kümmerten. Da deren größte Vergehen nach Zajíc der konfessionellen Zerrüttung und der Abkehr von den alten guten Sitten entsprangen, sollten sie mit einer Verbesserung im Bereich von Glauben und Moral beginnen ${ }^{22}$.

Gerade hier identifizierte sich der katholische Aristokrat mit dem habsburgischen Programm einer Rekatholisierung der tschechischen Bevölkerung. Zajíc war freilich nicht so naiv anzunehmen, daß eine augenblickliche Konversion der Mehrheit der Ständegesellschaft zu erwarten sei. Die Vereinigung im Katholizismus blieb ein weit entferntes Ziel, und zwar bei Aufrechterhaltung des Religionsfriedens im Lande. Am Beginn des Renovationsprozesses sollte eine Umwertung der böhmischen/tschechischen Geschichte und ihrer Dominanten als Grundlage für eine nationale Ideologie stehen. Zajíc zufolge mußte der Hussitismus eine neue Interpretation erhalten, insbesondere dessen militärpolitische und nationale Aspekte. Johann Zajíc lehnte einen fortdauernden Enthusiasmus im Hinblick auf das hussitische Militärwesen ab, dessen antikirchliche und antideutsche Ausrichtung er als äußerst schädlich empfand. Die militärische Stärke, die die Tschechen im 15. Jahrhundert demonstriert hatten, sollte sich in der Mitte des 16. Jahrhunderts in die Dienste ehrenvollerer Ziele stellen. Die militärische Tradition sollte nämlich eine antitürkische Stoßrichtung erhalten, ebenso war vorgesehen, den tschechi-

\footnotetext{
20 J. Zajíc, Paměti, S. 52.

${ }^{21}$ Ausführlicher zu dieser Quelle Růžena DostáLovÁ, Eine alttschechische Übersetzung des „Briefes des Alexios I. Komnenos an Robert I. von Flandern“ aus dem 16. Jahrhundert, Byzantinoslavica 60, 1999, S. 469-484.

22 J. Zajíc, Paměti, S. 39-51.
} 
schen Nationalismus dahingehend zu modifizieren, daß aus der antideutschen eine antitürkische Ausrichtung würde. Der tschechische Sankt-Wenzels- und der universale Marienkult sollten einen Kontrast zum Hussitentum schaffen und der nationalen Ideologie einen neuen bzw. den aktuellen Bedürfnissen angepaßten geistigen Inhalt verleihen ${ }^{23}$.

Die stufenweisen Bemühungen um eine konfessionelle Einigung der böhmischen Gesellschaft setzte nach Johann Zajíc eine sittliche Reinigung voraus. Der böhmische Aristokrat teilte die kritische Haltung der Moralisten, die den Luxus der privilegierten Schichten geißelten, ihre Genußsucht, Völlerei und Trunksucht, Faulheit sowie gehaltlose Prahlerei. Gegen diese Laster, die den Zorn Gottes hervorriefen, stellte er das ideale Rittertum und die darin verkörperten Tugenden. Die Erneuerung des Ritterkodex' sowie die militärische Erziehung des Adels sollten der verschwendungssüchtigen Schlemmerei und Gleichgültigkeit gegenüber dem gemeinsamen Schicksal ein Ende setzen. Die Rückkehr in die „Fußstapfen unserer lieben Vorfahren“ sollte den Weg für eine erneuerte christliche Moral sowie zu einer wirkungsvollen Kampfbereitschaft des böhmischen Adels ebnen ${ }^{24}$.

Gegen Satan und Türken sollte sich auf die Seite von Christus und der Habsburger der katholische Ritter (miles Christianus) als Symbol der tschechischen Ständegesellschaft stellen. Der sittlich erneuerte, im lehnsrechtlichen Sinne seinem König ergebene und zum Kampf für die wahre Religion entschlossene Adelige sollte zum Verteidiger Mitteleuropas gegen den türkischen Ansturm aufsteigen. Ein solcher, die universalen christlichen Werte verteidigender Ritter sollte zwar die Würde seines, des Sankt-Wenzels-Volkes verteidigen, doch mußte er der hussitischen Vergangenheit und ihrer Folge, der Spaltung der böhmischen Gesellschaft in pluralitäre konfessionell-politische Lager, entsagen. Er sollte zugleich den tschechisch-deutschen Antagonismus überwinden, damit im Interesse der allgemeinen christlichen Werte die mitteleuropäischen Völker ihre Kräfte gegen den gemeinsamen türkischen Feind bündeln könnten ${ }^{25}$.

Von den fünf grundlegenden Fragen ließ Johann Zajíc lediglich die Beziehungen zwischen den Ländern der Böhmischen Krone außer acht, also eine Frage, die sich in der Mitte des 16. Jahrhunderts noch nicht als besonders drängend erwies. Seine Zukunftsvision war auf eine Harmonisierung der Beziehungen zwischen Herrscher und Ständen, zwischen Deutschen und Tschechen, und schließlich zwischen den Mitteleuropäern untereinander ausgerichtet, ohne daß er sich expressis verbis insgesamt mit den keineswegs konfliktfreien Verhältnissen zu den Polen und insbesondere den Ungarn beschäftigt hätte, und zwar mit der Absicht, deren Kräfte für eine gemeinsame Verteidigung gegen den äußeren „heidnischen“ Feind zu vereinigen. Das Übergehen der östlichen Nachbarn des böhmischen Staates fällt besonders deshalb ins Auge, da Johann Zajíc offenkundig aus den frühen Elementen der sarmatischen Ideologie schöpfte, und zwar zum einen auf der Grundlage direkter Kontakte mit dem Hof der böhmisch-ungarischen Jagiellonen und zum anderen auf der Grundlage der während der internationalen Begegnung in Wien

23 Ebd. S. 51, $57 \mathrm{f}$.

24 Ebd. S. 52.

25 Zur Verbreitung der Vorstellungen von einer christlichen Erneuerung der böhmischen Gesellschaft an der Wende vom Mittelalter zur Neuzeit vgl. Noemi REJCHRTová, Příspěvek k diskusi o „koexistenci či toleranci“ náboženských vyznání v 15.-17. století, Folia Historica Bohemica 15, 1991, S. 443-450. 
im Jahre 1515 erworbenen Erfahrungen. Aus diesem geistigen Milieu standen ihm besonders die Wertschätzung des Patriotismus und der ritterlichen Tugenden, der Kult des Adeligen als des Beschützers des christlichen Glaubens, die anti-osmanische Stoßrichtung, aber auch der starke Traditionalismus nahe ${ }^{26}$. Die frühsarmatischen Anregungen dienten hier zur Betonung dessen, was dem katholischen Traditionalisten in Böhmen ohnehin eigen war - der Rückkehr zur religiösen Eintracht, zu den ritterlichen Tugenden und der Fähigkeit, das christliche Mitteleuropa gegen äußere Feinde zu verteidigen. Die katholische Vision einer einheitlichen antitürkischen Allianz kehrte somit zu den spätmittelalterlichen Idealen zurück, gleichzeitig jedoch nahm sie die Erneuerung des böhmischen Katholizismus im Frühbarock vorweg.

\section{Die Evangelische Konföderation DER MitTELEURopÄischen LÄNDER}

Die Generation der böhmischen Aristokraten, die zur Zeit von Zajíc' Tod ins öffentliche Leben trat, besaß bereits abweichende Vorstellungen von einer künftigen Ordnung Mitteleuropas. Die Mehrzahl von ihnen akzeptierte die Existenz der Habsburgermonarchie als Realität und bemühte sich, in diesem Rahmen so deutlich wie nur möglich ihr Glaubensbekenntnis, ihren Stand, ihr Land oder auch die Böhmische Krone insgesamt zur Geltung zu bringen. Lediglich in Ausnahmefällen wich diese Adelsgeneration von der Vorstellung, die Dynastie der Habsburger habe in Mitteleuropa eine einmalige Mission zu erfüllen, ab, wie dies in den siebziger Jahren des 16. Jahrhunderts der Fall war. Damals, während des ersten und zweiten polnischen Interregnums, trat der mächtigste böhmische Aristokrat, Wilhelm von Rosenberg, mit dem Plan einer eigenen Kandidatur für den polnischen Thron auf. Er stieß dabei jedoch auf eine habsburgische Übermacht, reagierte folglich - im Unterschied zu seiner Anhängerschaft in Polen - zurückhaltender in der Frage einer Möglichkeit zur Bildung einer polnisch-böhmischen Union, nahm von seinen ambitionierten Plänen Abstand und baute sich innerhalb der stabilisierten mitteleuropäischen Monarchie eine exponierte Machtstellung auf ${ }^{27}$.

Aber nicht einmal die Stabilisierung dieser Monarchie wies einen einfachen linearen Verlauf auf, insbesondere als die dynastischen Streitigkeiten zu Beginn des 17. Jahrhunderts in eine ernsthafte Krise des habsburgischen Herrschaftssystems mündeten. In der böhmischen Aristokratie, die sich nunmehr bereits in der dritten Generation nach dem Tode von Johann Zajíc befand, bildeten sich zwei einander im Grunde genommen unversöhnliche Lager heraus. Das erste Lager, das aus Anhängern der streng zentralisierten habsburgischen Herrschaft sowie einer raschen, auch gewaltsamen Rekatholisierung bestand, hielt die politische Macht im Königreich Böhmen in Händen,

${ }^{26}$ Eingehender hierzu Jaroslav PÁNEK, Selbstdarstellung und politisches Programm eines tschechischen Aristokraten aus dem 16. Jahrhundert (Zur Frage des Frühsarmatismus im jagiellonischen Böhmen), in: Ludzie - Kościól - Wierzenia. Studia z dziejów kultury i społeczeństwa Europy Środkowej (średniowiecze - wczesna epoka nowożytna). Profesorowi Stanisławowi Bylinie w 65 rocznicę urodzin, Warszawa 2001, S. 489498.

27 Josef MACŮREK, Čechové a Poláci v 2. pol. XVI. století (1573-1589). Tři kapitoly z dějin česko-polské politické vzájemnosti, Praha 1948, S. 35-136; Jaroslav PÁNEK, Osobowość Wilhelma z Rożemberka, polityka czeskiego doby Renesansu i kandydata do korony polskiej, in: Kultura staropolska - kultura europejska. Prace ofiarowane Januszowi Tazbirowi w siedemdziesiątą rocznice urodzin, Warszawa 1997, S. 287-297; ders., Vilém z Rožmberka. Politik smíru, Praha 1998, S. 175-201. 
während das andere Lager, repräsentiert durch die reichsten Adeligen des nichtkatholischen Glaubensbekenntnisses, hierzu in Opposition stand. Am Ende der Regierung Rudolfs II., in den Jahren 1608-1611, spitzten sich die Gegensätze derart zu, daß zu den gewohnten Herrschaftsinstitutionen in Böhmen alternative Organe entstanden, die die reale Macht der protestantischen Stände zum Ausdruck brachten ${ }^{28}$. Der evangelische „Staat im Staate“ wurde die institutionelle Verkörperung der tiefen Gegensätze innerhalb Böhmens und der Habsburgermonarchie, der Widersprüche, die folgerichtig zum entscheidenden Konflikt führten - dem böhmischen Ständeaufstand 1618-1620 und dem damit eingeleiteten Dreißigjährigen Krieg ${ }^{29}$.

In der ersten Phase des Ständeaufstands (1618-1619) wurde das Königreich Böhmen von einem Direktorium regiert, hatte also im Grunde genommen ein republikanisches System. Dessen Ziel bestand jedoch nicht darin, dauerhaft eine Republik zu errichten, sondern im Gegenteil die dualistische Monarchie zu erneuern, freilich mit einem außerordentlich starken Einfluß der Stände. Am Vorabend der Wahl eines neuen Herrschers und der damit verbundenen Rückkehr zur Königsherrschaft legten die böhmischen Aufständischen eine Verfassung zur Annahme vor, die Böhmische Konföderation (Confoederatio Bohemica, Ceská konfederace), die den Höhepunkt des verfassungsmäßigen Denkens in Böhmen in der frühen Neuzeit darstellt ${ }^{30}$.

Diese Böhmische Konföderation vom 31. Juli $1619^{31}$, die den Titel einer „Magna Charta der evangelischen Ständebewegung“ erhielt ${ }^{32}$, versuchte an erster Stelle auf gänzlich neue Art und Weise die offenen strukturellen Probleme des böhmischen Staatswesens zu lösen. Sie ging dabei davon aus, daß die bisherigen konfliktreichen Beziehungen zwischen Herrscher und Ständeopposition in jüngster Vergangenheit beinahe zum Zerfall der Länder der Böhmischen Krone geführt hätten, nämlich durch die Bildung der ungarischösterreichisch-mährischen Konföderation des Jahres 1608 und daß es folglich notwendig sei, den böhmischen Staat - gegebenenfalls auch dessen Verbindung mit weiteren Ländern der bisherigen Habsburgermonarchie - auf anderen Grundlagen zu begründen ${ }^{33}$.

28 Eingehender hierzu Jaroslav PáNEK, Politický systém předbělohorského českého státu, Folia Historica Bohemica 11, 1987, S. 41-101, insbesondere S. 57-59.

29 Auch in diesem Fall kann ich aus der umfangreichen Literatur zur dieser Thematik lediglich auf einige besonders gewichtige Arbeiten verweisen: Antonín GindELy, Dějiny českého povstání léta 1618, I-III, Praha 1870-1878; František HruBÝ, Ladislav Velen z Žerotína, Praha 1930; Noemi Reschrtová, Václav Budovec z Budova, Praha 1984; Josef JANÁČEK (Hg.), Pavel Skála ze Zhoře, Historia česká. Od defenestrace k Bílé hoře, Praha 1984; Josef JANÁČEK, České stavovské povstání 1618-1620 (Otázky a probémy), Folia Historica Bohemica 8, 1985, S. 7-41; ders., Rudolf II. a jeho doba, Praha 1987; Josef PoLIŠEnskÝ, Tragic Triangle. The Netherlands, Spain and Bohemia 16171621, Prague 1991.

30 Eingehender hierzu Jaroslav PánEK, Republikanské tendence ve stavovských programech doby předbělohorské, Folia Historica Bohemica 8, 1985, S. 43-62.

31 Die beste Edition der böhmischen Konföderationsurkunde besorgte František KamENíČEK, Zemské sněmy a sjezdy moravské, II, Brno 1902, S. 649-669.

32 Josef VÁLKA, Morava ve stavovské konfederaci roku 1619 (Pokus o vytvoření paralelních církevních a politických struktur v Čechách a na Moravě), Folia Historica Bohemica 10, 1986, S. 333-349; das Zitat auf S. 333.

33 „... léta šestnácti stého osmého již hrubě se k tomu schylovalo, že jest to celé tělo [Koruny české] roztrženo býti mělo... Protož jsou výš oznámené země společně již před několika lety za nevyhnutedlnou potřebu uznaly, aby ještě bližší a to takové sjednocení a svazek mezi sebou učinily..." (,... das Jahr Sechzehnhundertacht neigte bereits stark dazu, daß dieser gesamte Corpus [der Böhmischen Krone] zerschlagen werden soll- 
Die neue Grundlage des Staatenbundes wurden die freiwillig vereinten Länder, und zwar vornehmlich die fünf Länder des böhmischen Staatswesens, denen sich noch weitere mitteleuropäische Länder aus eigenem Willen anschlossen. Am weitesten ging in dieser Richtung Oberösterreich, das am 16. August 1619 einen weitreichenden Vertrag mit der Böhmischen Krone schloß; eine lockerere Vertragsform wählte hingegen Niederösterreich ${ }^{34}$. Dennoch stand der gesamte Konföderationsbund zumindest theoretisch auch weiteren Teilen Österreichs und Ungarns offen ${ }^{35}$. Da die kriegerischen Verhältnisse in den Jahren 1619 und 1620 keine konsequente Realisierung der Konföderationsverträge in der verfassungsmäßigen und politischen Praxis erlaubten, und da es den Habsburgern gelang, den ständischen Widerstand bereits im November 1620 zu zerschlagen, konnten die weitgesteckten Absichten nicht in vollem Maße eine Verwirklichung erfahren. Wir werden deshalb an dieser Stelle weder Detailfragen der Legalität und der Machtausübung noch die natürlichen Unterschiede zwischen den böhmischen und österreichischen Ländern weiter verfolgen, sondern lediglich die grundlegende Vorstellung hinsichtlich einer möglichen Ordnung der mitteleuropäischen Länder.

Grundlegendes Element dieser radikalen Zukunftsvorstellung war eine einseitige Betonung des ständischen Prinzips, das ein Übergewicht über das monarchische Prinzip erlangen sollte. Die königliche Gewalt sollte zwar erhalten bleiben, freilich nur als repräsentatives und ausgleichendes Element des Staatsorganismus. Der König sollte weiterhin durch freie Wahl und konsequente Kontrolle von seiten der Ständeorgane, insbesondere der sogenannten Defensoren, eingebunden bleiben; würde er sich gegen die Konföderationsverfassung stellen, war ein Vorgehen gegen ihn auf der Grundlage des ius resistendi vorgesehen. Die Vertragstheorie zwischen Herrscher und Ständen bildete somit das entscheidende Prinzip, auf dem die neue staatliche oder sogar überstaatliche Ordnung Mitteleuropas basieren sollte ${ }^{36}$.

Eine weitere Grundlage bildete die Gleichberechtigung der Mitgliedsländer bzw. der „selbständigen konföderierten Ständestaaten“"37, die die Widersprüche zwischen dem Königreich Böhmen im engeren Sinne sowie den vier inkorporierten Ländern lösen sollte - Gegensätze, die bereits seit dem 15. Jahrhundert bestanden. Für alle Länder war weiterhin die Verfassung bzw. der Konföderationsvertrag bindend, alle hatten sich an der Wahl des Herrschers sowie an seiner Kontrolle zu beteiligen, ebenso an der Bildung gemeinsamer Organe (insbesondere des Generallandtags und gemeinsamer De-

te...Daher haben die oben angezeigten Länder gemeinsam bereits vor einigen Jahren es als unumgängliches Bedürfnis erkannt, daß sie schon bald eine solche Vereinigung und einen solchen Bund unter sich schließen sollten“); Eingangspassage zur Konföderationsurkunde: F. KAMENÍčEK, Zemské sněmy, II, S. 650.

34 Karolina ADAmová, K otázce česko-rakouského a česko-uherského konfederačního hnutí v letech 1619-1620, Právněhistorické studie 29, 1989, S. 79-90; dies., K historii evropského federalismu, Praha 1997, S. 56-61 (dort auch Verweise auf Quelleneditionen und weitere Literatur); Joachim BAHLCKE, Regionalismus und Staatsintegration im Widerstreit. Die Länder der Böhmischen Krone im ersten Jahrhundert der Habsburgerherrschaft (1526-1619), München 1994, S. 400-445.

35 Štefan KRIvošík, Príspevok k dejinám stavovskej konfederácie českých a uhorských stavov z r. 1620, Právnické štúdie 7, 1959, S. 147-187.

${ }^{36}$ Eine ausführliche rechtshistorische Analyse lieferte: Karel MaLÝ, Změny státního zřízení v českém stavovském povstání, Folia Historica Bohemica 8, 1985, S. 63-88, insbesondere S. 78 .

37 K. MaLÝ, Změny státního zřízení, S. 67, 78. 
fensoren), sowie an der gemeinsamen Verteidigung des Staatsgebietes. Auf der Basis der Anstrengungen, Gleichgewicht und Autonomie der Länder mit der Einheit des Staates in Einklang zu bringen, entstand ein neues ständisch(kon)föderatives Modell der staatlichen Einheit, das den Ausgangspunkt für eine Neuorganisierung Mitteleuropas bilden sollte ${ }^{38}$.

Das dritte entscheidende Prinzip war die eindeutige Lösung der Konflikte zwischen Protestanten und Katholiken zu Gunsten der protestantischen Mehrheit der Bevölkerung. Die Konföderation ging nicht soweit wie der Augsburger Religionsfrieden im Heiligen Römischen Reich von 1555 und zwang die Anhänger der katholischen Minderheit nicht zum Übertritt zum einzig legalen Glauben bzw. zum Verlassen des Landes. Daher erscheint auch die Annahme, es habe sich um eine „Diktatur der Evangelischen gegenüber den Katholiken" gehandelt, ein wenig übertrieben ${ }^{39}$. Die Konföderation tendierte freilich zu einer einseitigen Bevorzugung der protestantischen Mehrheit gegenüber der katholischen Minderheit. Als Diskriminierung läßt sich zwar nicht die Pflicht der Katholiken ins Feld führen, wortgetreu einen Eid auf die Konföderation abzulegen ${ }^{40}$, da es sich um einen Ausdruck der Loyalität gegenüber dem Staat handelte; ein offenkundiges Zeichen für die Ungleichheit der Bekenntnisse war jedoch die taxative Beschränkung einiger oberster Landesämter ausschließlich auf Protestanten ${ }^{41}$. Die Nichtgleichberechtigung betraf nicht allein den Adel, sondern auch die Bürger, deren katholischer Teil in Fragen der städtischen Selbstverwaltung sichtbare Benachteiligungen in Kauf nehmen mußte ${ }^{42}$. Die Vorrechte der Majorität gegenüber der Minorität waren objektiv durch die Kriegsereignisse begründet, in deren Verlauf jene Prinzipien formuliert wurden, zum anderen aber auch durch das illoyale Auftreten vieler katholischer Aufstandsgegner. Dennoch kann nicht geleugnet werden, daß es sich um eine offenkundige konfessionelle Einengung der ständischen Vision handelte. Ähnlich wie Johann Zajíc eine künftige Vereinigung im katholischen Glauben voraussetzte, beabsichtigten auch die Aufständischen stillschweigend Konversionen politisch ambitionierter Katholiken zum evangelischen Glauben zu unterstützen. Die konfessionell geprägte Zeit bedingte so in beiden Zukunftsvisionen des böhmischen Staates und Mitteleuropas ein gewisses Maß an Intoleranz ${ }^{43}$.

Die vierte Grundlage dieser Vision bildete die gemeinsame Verteidigung der Konföderation gegen äußere Feinde. Im Unterschied zu Johann Zajíc erblickten die nichtkatholischen Stände ihren Hauptfeind nicht in den Türken, in denen sie schließlich sogar einen möglichen Verbündeten im antihabsburgischen Kampf sahen ${ }^{44}$, sondern in den Habsburgern. Nach langjährigen er-

38 Vgl. J. VÁLKA, Morava ve stavovské konfederaci, S. 338.

39 So interpretiert die entsprechenden Bestimmungen der Böhmischen Konföderation K. MaLÝ, Změny státního zřízení, S. 69.

40 Confoederatio Bohemica, Artikel XII-XIV; F. KameníčEK, Zemské sněmy, II, S. 654 f.

41 Confoederatio Bohemica, Artikel XVI; F. KAMENíčEK, Zemské sněmy, II, S. 655.

42 Confoederatio Bohemica, Artikel XVIII-XIX; F. KAmEníčeK, Zemské sněmy, II, S. $655 \mathrm{f}$.

43 Vgl. die neueste Würdigung der Confoederatio Bohemica im Artikel von Josef VÁLKA, Konfederace z roku 1619 ve vývoji teritoriální a náboženské struktury České koruny, in: Karel Malý - Jaroslav Pánek (Hrsg.), Vladislavské zřízení zemské a počátky ústavního zř́zení v českých zemích (1500-1619), Praha 2001, S. 193-202.

${ }^{44}$ H. Forst, Der türkische Gesandte in Prag 1620 und der Briefwechsel des Winterkönigs mit Sultan Osman II., Mitteilungen des Instituts für österreichische Geschichtsforschung 16, 1895, S. 566-581; Noemi ReJchrTová, Václav Budovec z Budova, Praha 1984 , S. 137 f., $155 \mathrm{f}$. 
folglosen Versuchen, eine gemeinsame Defension der böhmischen Länder auszuhandeln, durch die die Ständeopposition den Habsburgerkönigen entgegentreten konnte ${ }^{45}$, kam es im Jahre 1619 nach reibungslosen Verhandlungen zum Abschluß eines Vertrags über die Finanzierung und Organisation eines Heeres, eine gemeinsame Befehlsgewalt sowie eine gegenseitige Unterstützung mit allen zur Verfügung stehenden Mitteln ${ }^{46}$. Ungewöhnlich war die beabsichtigte militärische Solidarität, die zu einer erfolgreichen Abwehr des habsburgischen Angriffs auf die böhmischen Länder und in der Zukunft jedoch auch zur Stabilisierung des Friedens in Mitteleuropa beitragen sollte. Diese Solidarität der evangelischen Glaubensgenossen machte auch an den Grenzen der Böhmischen Krone nicht halt und schloß expressis verbis sowohl Tschechen als auch Deutsche ein. Auch wenn es zwischen beiden Ethnien nicht einmal zu Beginn des Dreißigjährigen Krieges an Antagonismen mangelte $^{47}$, sollten die gemeinsamen religiösen und politischen Interessen konsequent den nationalen übergeordnet sein.

Die Staatskonstruktionen, die die Böhmische Konföderation und die an diese anknüpfenden Verträge betrafen und denen diese den Weg in die Zukunft wiesen, waren der konsequenteste Ausdruck des Monarchomachismus in der böhmischen/tschechischen Geschichte ${ }^{48}$. Die an den Rand gedrängte königliche Gewalt war in keinem Falle mit der habsburgischen Konzeption Mitteleuropas vereinbar. Die politische Vision der Stände, verfassungsmäßig verankert und partiell auch umgesetzt, focht mit der habsburgischen Gewalt einen Existenzkampf aus und unterlag dieser im November 1620 vollständig. Die vernichtende Niederlage und die sich daran anschließende Ausschaltung aller antihabsburgischen Oppositionskräfte garantierten, daß in Zukunft niemand mehr den Versuch wagen würde, an das Projekt des Jahres 1619 in irgendeiner Form anzuknüpfen.

\section{ZusammenFassung}

Zwischen beiden frühneuzeitlichen Zukunftsvisionen Mitteleuropas lag der Unterschied von zwei bis drei Generationen; es überrascht daher nicht, daß sie sich sowohl in ihren geistigen Wurzeln als auch vom Werdegang der Autoren her unterscheiden. Im ersten Fall handelt es sich um die Sicht eines Aristokraten, der durch seine kulturellen Interessen sowie seine Weitsicht in vielem den Horizont der zeitgenössischen Adelsgesellschaft überstieg, im zweiten Fall geht es um die kollektive Vorstellung der oppositionellen antihabsburgischen Stände. Schon allein deshalb unterscheiden sich die Vorstellungen

45 Miloslav Volf, Pokusy o společnou defensi České koruny v poslední třetině XVI. století. Příspěvek k politicko-vojenské historii, in: K dějinám československým v období humanismu. Sborník prací věnovaných Janu Bedřichu Novákovi k 60. narozeninám, Praha 1932, S. 315-342.

46 Confoederatio Bohemica, Artikel LXX-LXXXVI; F. KAMENíčEK, Zemské sněmy, II, S. 665-667.

47 In ihren Werken äußerten sich von tschechischer Seite hierzu insbesondere Pavel Stránský (Na nedbalého Čecha učiněný okřik, 1618) und Pavel Ješín (kommentierte Ausgabe der Kronika česká tak řečeného Dalimila, 1620); moderne Editionen: Bohumil Ryвa (Hg.), Pavel Stránský ze Zápské Stránky, Český stát. Okřik, Praha 1953, S. 361-380; Jiří DAŇHELKa (Hg.), Die alttschechische Reimchronik des sogenannten Dalimil, herausgegeben von Pavel Ješín z Bezdězí 1620, München 1981.

48 Rudolf Stanka, Die böhmischen Conföderationsakte von 1619, Berlin 1932; K. MaLÝ, Změny státního zřízení, S. 68. 
der Schöpfer dieser Konzeptionen in der Bewertung der Rolle von Herrscher und Ständen, Katholiken und Protestanten, der Habsburgermonarchie und des Osmanischen Reiches. Dennoch findet sich zwischen ihnen eine grundlegende Übereinstimmung, und zwar im Bemühen, die Grundfrage der damaligen Zeit zu beantworten, wenn auch zumeist auf diametral entgegengesetzte Weise. Sofern zwischen beiden Zukunftsvisionen auch eine sachliche Übereinstimmung besteht, dann beruht diese auf der Überzeugung, daß eine bessere Gestalt Mitteleuropas nicht anders denkbar sei als durch eine grundlegende Verständigung zwischen Tschechen und Deutschen bzw. den Deutsch sprechenden Nachbarn, im breiteren Kontext dann zwischen den mitteleuropäischen Völkern. Hierin ist vielleicht auch ein gewisser zeitloser Wert dieser temporär begrenzten Konzepte verankert. Dank dieser Tatsache vermögen diese Vorstellungen über die Grenzen der Jahrhunderte hinweg auch ihre Anziehungskraft für die Forschung an der Schwelle vom 20. zum 21. Jahrhundert bewahren. 